\title{
Unusual High Bifurcation Of Common Carotid Artery Among Eastern Population- A Case Study.
}

\author{
${ }^{1}$ Dr. Shweta Solan, ${ }^{2}$ DR. Gokul Krishna Reddy Nune. \\ ${ }^{1,2}$ Department of anatomy, kallinga institute of medical sciences, Bhubaneswar, India.
}

\begin{abstract}
Variation of the common carotid artery, including high origin, rare absence, low bifurcation \& also anomolous origins of common carotid artery are very common. Knowledge of carotid bifurcation is important for vascular surgical procedures, such as carotid endarterectomy or radical neck dissection, catheterization and aneurysms ${ }^{1}$. The aim of this study was to describe the level of common carotid artery bifurcation. 50 adult cadavers were dissected and variation in pattern of common carotid artery bifurcation were noted.
\end{abstract}

Keywords: Common carotid artery, Bifurcation, Thyroid cartilage

\section{Introduction}

The common carotid artery $[\mathrm{CCA}]$ and its branches are the main arterial supply to the head and neck ${ }^{2}$. During radical neck surgeries, the common carotid arteries are important landmarks, defining the plane of the dissection.Evaluation of the carotid bifurcation level can be done with non invasive techniques and external anatomical landmarks can be clinically useful in predicting the bifurcation level of the carotid artery. Accurate level of bifurcation can be devised by dissection method in nonliving. Increase variations in the branching patterns may increase the risk of vascular accidents during surgical procedures in the neck and also angiographic aberrations ${ }^{3}$

\section{Normal anatomy}

The CCA is a large bilateral vessel supplying head, neck \& brain. The right \& left carotid arteries differ in length \& origin. The right carotid exclusively originates from brachiocephalic trunk behind the right sternoclavicular joint. The left carotid artery originates from the aortic arch immediately posterolateral to the brachiocephalic trunk. At the level of upper border of thyroid cartilage,[ approximately at a level midway between the third and fourth cervical vertaebrae $]$ the CCA divides into external and internal carotid arteries. ${ }^{4}$ The bifurcation of CCA ordinarily occurs, however, at approximately the level of the interval between the superior border of thyroid cartilage and inferior border of the hyoid bone. ${ }^{5}$

\section{Materials and methods}

During routine dissection teaching to MBBS students at KIMS, BBSR, 50 adult cadavers[irrespective of sex] were dissected and pattern of bifurcation of CCA were noted. Hundred carotid vessels (50left and 50right), in 50 cadavers were dissected for the purpose of data collection. A descriptive cross sectional study was carried out. Dry and macerated cadaveric specimens were excluded from the study. Carotid triangles were exposed by giving skin incisions and removing skin flaps from chin to suprasternal notch and along lower border of mandible. Bifurcation of CCA was exposed and level of bifurcation were noted. High levels of bifurcation were considered to be above c3-4 vertebral junction. Anterior landmark for c3-4 junction was upper border of thyroid cartilage. Out of fifty, one cadaver showed unilateral high bifurcation of CCA and other four showed bilateral high bifurcation of CCA. Other 44 cadavers showed normal bifurcation at upper border of lamina of thyroid cartilage, at $\mathrm{c} 3-\mathrm{c} 4$ level. Details of these variations were noted and distance from upper border of thyroid cartilage were measured using a ruler..

\section{Observations}

1] One cadaver showed unilateral high bifurcation of CCA at upper border of hyoid bone at $\mathrm{c} 2$ level on right side.[ refer- fig.-1]. Distance measured from upper border of thyroid cartilage was $2.5 \mathrm{~cm}$. On left side, artery bifurcated normally at c3 -c4 level.[ refer fig.- 2].

2] One cadaver showed bilateral high bifurcation of CCA at angle of mandible at c1-c2 level. Distance measured from upper border of thyroid cartilage was $4.1 \mathrm{~cm}$.[ refer fig.-3]

3] In other four cadavers, CCA bifurcation was slightly above upper border of thyroid cartilage at c3 level. Distance measured from upper border of thyroid cartilage was ranging from 0-5 to $1 \mathrm{~cm}$.[ refer fig.-4].

4] In rest 44 cadavers, CCA bifurcation was normal at c3-c4 level. 


\section{Result}

Eleven bifurcations [11\%] showed high bifurcation of CCA. Out of it, $1 \%$ showed bifurcation at $\mathrm{c} 2$ level and 2\% showed bifurcation at c1- c2 level. Another 8\% showed bifurcation at c3 level. Others showed normal level of bifurcation.

\begin{tabular}{|l|l|l|}
\hline LEVEL OF BIFURCATION & NUMBER & PERCENTAGE\% \\
\hline C1-C2 & 2 & $2 \%$ \\
\hline C2 & 1 & $1 \%$ \\
\hline C3 & 8 & $8 \%$ \\
\hline C3-C4[ normal] & 88 & $88 \%$ \\
\hline & & \\
\hline
\end{tabular}

\section{Discussion}

The present study recorded a frequency of $11 \%$ for high bifurcation of CCA at variable levels. Out of it, $2 \%$ showed bifurcation at c1-c2 level, $1 \%$ showed bifurcation at c2 level, and $8 \%$ showed bifurcation at c3 level. Variation in level of bifurcation on two sides was noted in one cadaver, where on right side bifurcation was at $\mathrm{c} 2$ level and on left side was normal at $\mathrm{c} 3-\mathrm{c} 4$ level. In eastern population, $11 \%$ high CCA bifurcation is not a very big number but these chances have to be kept in mind while performing diagnostic, or therapeutic procedures on carotids.

A study on human foetuses showed $60 \%$ of CCA bifurcation at the level of $\mathrm{C} 3$ on the left side and $55 \%$ on the right side. Bilateral high CCA bifurcation, $1 \mathrm{~cm}$ above the greater cornu of the hyoid bone and $2 \mathrm{~cm}$ above the superior border of the lamina of the thyroid cartilage was reported ${ }^{6,7}$. Bilateral CCA bifurcation at the level of $\mathrm{C}_{2}^{8}$ was reported. A case showed the bilateral high CCA bifurcation, above the angle of the mandible (C2), that is $3.6 \mathrm{~cm}$ above the superior border of the thyroid cartilage. ${ }^{9}$

Variable incidence for $\mathrm{C} 3 / \mathrm{C} 3-4$ bifurcation levels among foetuses ${ }^{10}$ have been indicated by earlier gross anatomical studies and those examining angiographs Incidence of C 3 bifurcation was noted to be $55 \%$ by Zumre et $a l^{I 0}$ while the angiographic study by Hayashi et $\mathrm{al}^{11}$ found C 3 termination in 100\% adult carotids. C 3 termination occurs in $57.5 \%$ of carotid vessels among adult Japanese ${ }^{12}$. Smith and $\operatorname{Larsen}^{13}$, reported, the left carotid bifurcation to be higher than the right in 50\% of the cases and the right bifurcation higher than left in $22 \%$ of the cases. Clinical challenges are posed by such accounts as they may predispose to angiographic data misinterpretation ${ }^{10}$ and surgical complications ${ }^{14}$.

Increased chances of impingement of high CCA bifurcation are there, by intra-articular screws during procedures on cervical vertebrae ${ }^{15}$. Exact bifurcation site and CCA variations are clinically important in many other procedures, such as ligation of the external carotid artery, intra-arterial administration of chemotherapeutic agents, interpretation of digital subtraction angiography, and during radical neck dissection ${ }^{16-18}$.

\section{References}

[1] Ord RA, Ward -Booth RP. Anamolies of the common carotid artery: A rare complication of radical neck dissection. Brit. J. Oral Max .Surg. 1986; 24(6): 405 - 9.

[2] Lucev N, Bobinac D, Maric I, Drescik I (2000) Variations of the great arteries in the carotid triangle. Otolaryngol Head Neck Surg 22: 590-591.

[3] Schulz, u.g.r. and rothwell,P.M. sex differences in carotid bifurcation anatomy and the distribution of atherosclerotic laque. Stroke. 2001;32:15250.

[4] Susan Standring; Gray's Anatomy. Head and neck - overview and surface anatomy 40 Ed. Elsevier,Churchill Livingstone 2008, pp 409.

[5] Henry Hollinshead;. Anatomy For Surgeons.The head and neck. Chapter 9.the neck. 3 Edition. Vol 1. Harper and RowPublishers, Philadelphia 1982, pp - 461.

[6] Kishve PS, Kishve SP, Joshi M, Syed MMA, Kalakoti P. An unusual branching pattern of the common and external carotid arteries in a human cadaver-A case report. AMJ. 2011; 4, 4:180-82.

[7] Mamatha T, Rajalakshmirai, Prabhu LV, Hadimani G A, Jiji P J, Prameela MD. Anomalous branching pattern of the external carotid artery; A case report. Romanian Journal of Morphology and Embryology. 2010; 51(3): 593-95.

[8] Anu VR, Pai MM, Rajalakshmi R, Latha V P, Rajanigandha V, D'Costa. Clinically-relevant variations of the carotid arterial system. Singapore Med J. 2007; 48(6): 566.

[9] D. Vinaitha, K. Suba Anandhi, R. Sharmila Saran, Lakshmi Ramanathan, Aruna Subramaniam. HIGH BIFURCATION OF THE COMMON CAROTID ARTERY AND LOOPING OF THE EXTERNAL CAROTID ARTERY - A CASE REPORT. Journal of Clinical and Diagnostic Research [serial online] 2012 May [cited: 2014 Mar 14 ]; 6:462-464.

[10] Zumre, O ., S albacak, A ., C icekcibasi, A .E., et al.Investigation of the bifurcation level of the common carotid artery and variations of the branches of the external carotid artery in human fetuses. Ann. Anat.2005; 187: 361-369.

[11] Hayashi, N ., Hori, E., O htani, Y ., et al. Surgical anatomy of the cervical carotid artery for carotid endarterectomy. Neurol. Med. Chir. (Tokyo). 2005; 45: 25-29.

[12] Ito, H., Mataga, I ., Kageyama, I ., et al. Clinical anatomy in the neck region-the position of external and internal carotid arteries may be reversed. Okajimas Folia Anat. Jpn. 2006; 82: 157-167.

[13] Smith, D . and L arsen, J. O n the symmetry and asymmetry of the bifurcation of the common carotid artery. A study of bilateral carotid angiograms in 100 adults. Neuroradiol. 1979; 17: 245-247.

[14] Schulz, U.G.R. and R othwell, P.M. S ex differences in carotid bifurcation anatomy and the distribution of atherosclerotic plaque. Stroke. 2001; 32: 1525.

[15] Currier, B.L., T odd, L.T., Maus, T .P., et al. Anatomic relationship of the internal carotid artery to the C 1 vertebra: A case report of cervical reconstruction for chordoma and pilot study to assess the risk of screw fixation of the atlas. Spine. 2003; 28: E461-E467. 
[16] pharyngeal artery and anomalous origin of ascending pharyngeal artery and anomalous branching pattern of external carotid artery. Surg Radiol Anat 23: 123-125.

[17] Riles TS, Berenstein A, Fischer FS, Persky MS, Madrid M (1993) Reconstruction of the ligated external carotid artery for embolization of cervicofacial arteriovenous malformations. J Vasc Surg 17: 491-498.

[18] Roberts LK, Gerald B (1978) Absence of both common carotid arteries. AJR Am J Roentgenol 130: 981-982.

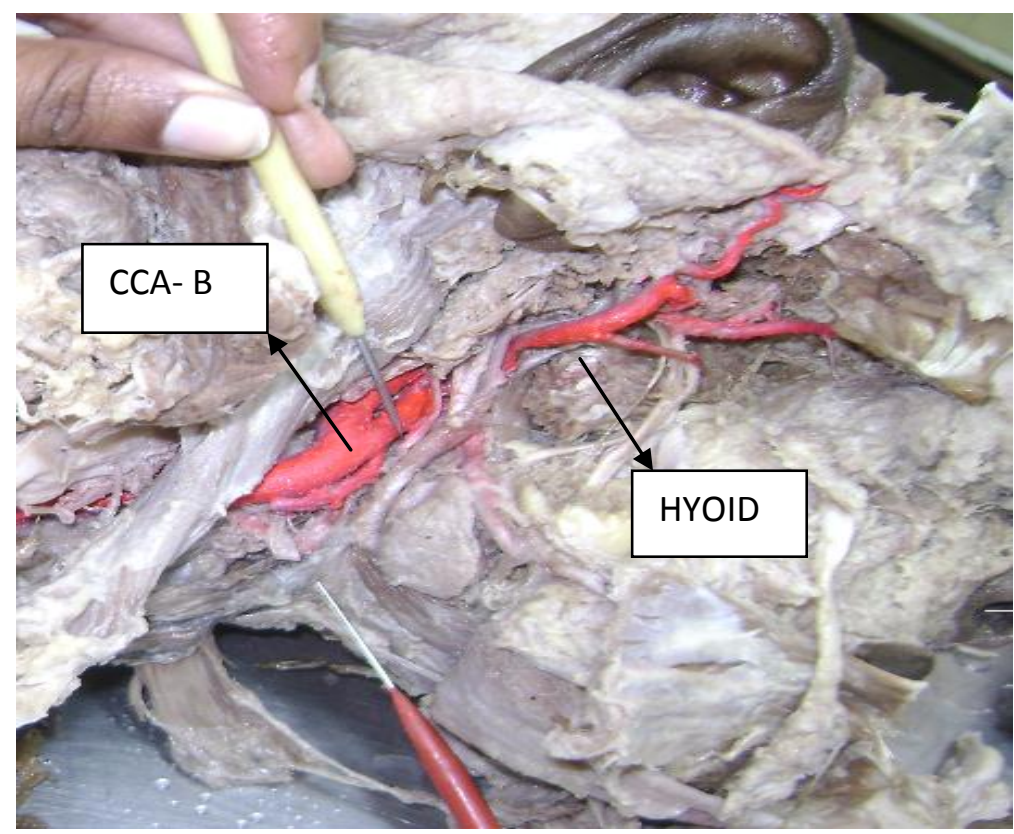

FIG-1]- showing CCA bifurcation[CCA-B] at level of hyoid bone at c2 level on right side.

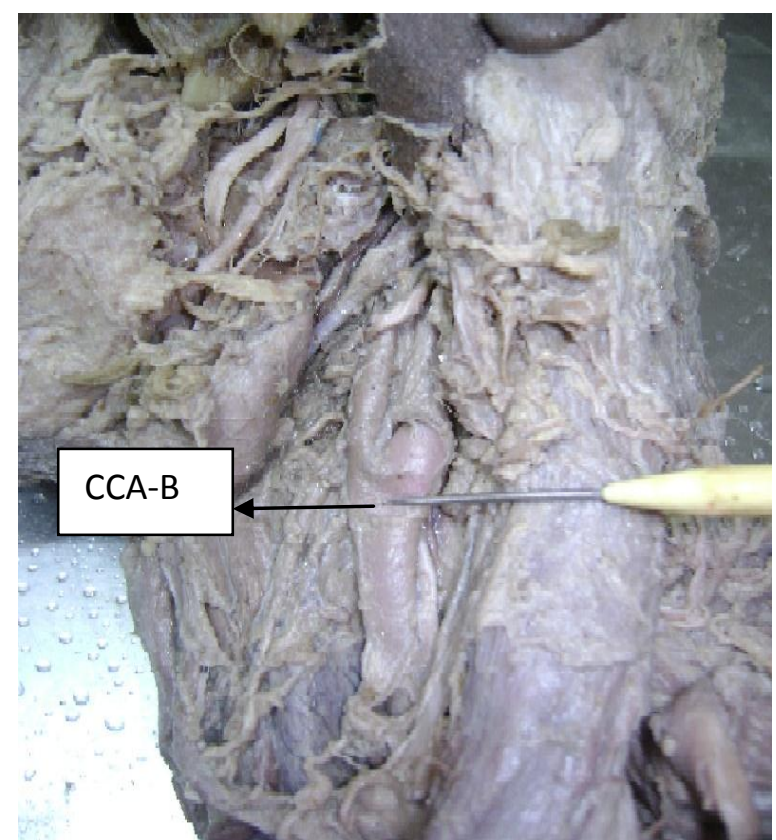

FIG.-2- Showing normal CCA bifurcation at c3-c4 level on left side. 


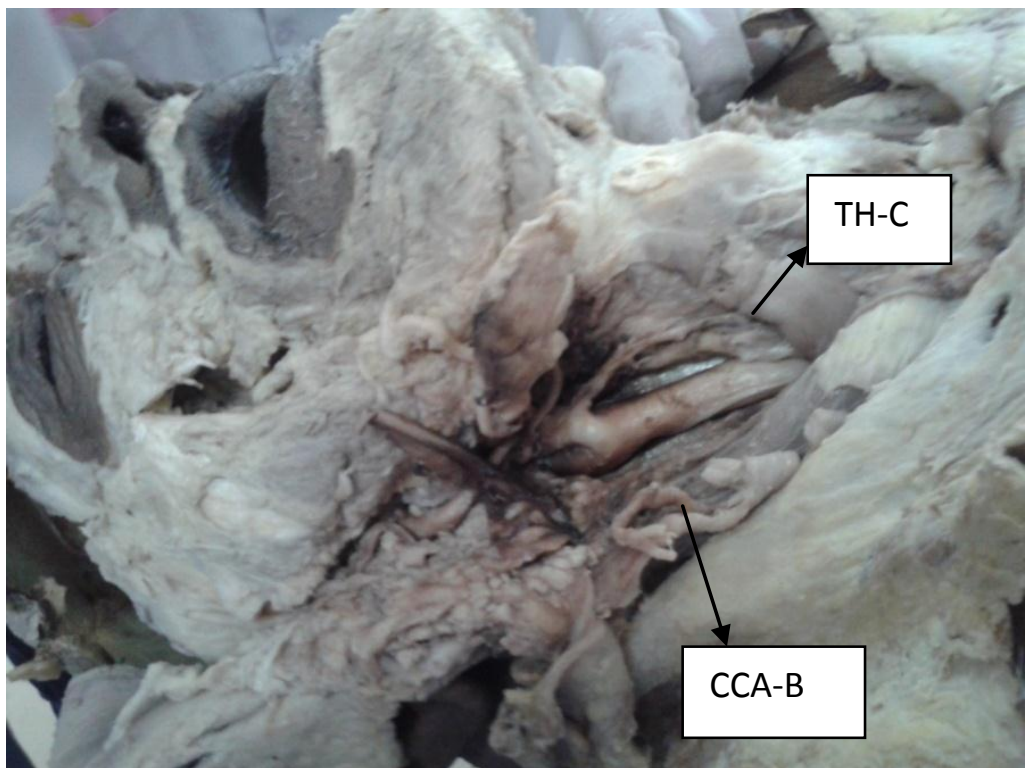

FIG.-3- Showing high CCA bifurcation above angle of mandible at c1-c2 level. TH-C- thyroid cartilage.

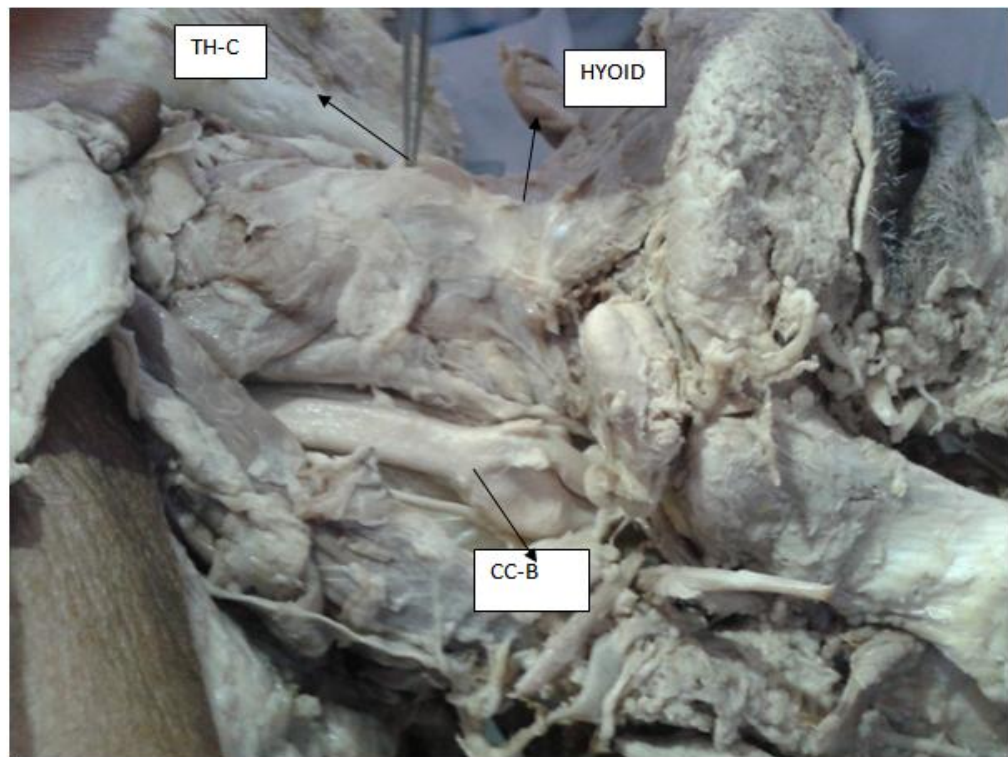

FIG.-4- Showing CCA bifurcation at lower border of hyoid at c3 level. 